\title{
GEICO (Spanish Group for Investigation on Ovarian Cancer) treatment guidelines in ovarian cancer 2012
}

\author{
A. González Martín • A. Redondo • M. Jurado - A. De Juan • I. Romero • \\ I. Bover · J. M. Del Campo • A. Cervantes · Y. García · J. A. López-Guerrero • \\ C. Mendiola $\cdot$ J. Palacios $\cdot$ M. J. Rubio $\cdot$ A. Poveda Velasco \\ Received: 20 December 2012/ Accepted: 21 December 2012/Published online: 7 March 2013 \\ (C) The Author(s) 2013. This article is published with open access at Springerlink.com
}

\begin{abstract}
In 2006, under the auspices of The Spanish Research Group for Ovarian Cancer (Spanish initials GEICO), the first "Treatment Guidelines in Ovarian Cancer" were developed and then published in Clinical and Translational Oncology by Poveda Velasco et al. (Clin Transl Oncol 9(5):308-316, 2007). Almost 6 years have elapsed and over this time, we have seen some important developments in the treatment of ovarian cancer. Significant changes were also introduced after the GCIG-sponsored 4th Consensus Conference on Ovarian Cancer by Stuart et al. (Int J Gynecol Cancer 21:750-755, 2011). So we decided to update the treatment guidelines in ovarian cancer and, with this objective, a group of investigators of
\end{abstract}

\section{A. González Martín (ه)}

Medical Oncology Department, MD Anderson Cancer Center,

C/Arturo Soria, 270, 28033 Madrid, Spain

e-mail: agonzalezm@seom.org

\section{A. Redondo}

Medical Oncology Department, University Hospital La Paz,

Madrid, Spain

\section{Jurado}

Department of Gynecology, School of Medicine,

University of Navarra, Pamplona, Spain

\author{
A. De Juan \\ Department of Medical Oncology, University Hospital \\ Marqués de Valdecilla, Santander, Spain

\section{Romero} \\ Department of Medical Oncology, Fundación Instituto \\ Valenciano de Oncología, Valencia, Spain \\ I. Bover \\ Medical Oncology Department, Hospital Son Llàtzer, \\ Palma de Mallorca, Islas Baleares, Spain
}

the GEICO group met in February 2012. This study summarizes the presentations, discussions and evidence that were reviewed during the meeting and during further discussions of the manuscript.

Keywords Ovarian cancer - Treatment guidelines · Chemotherapy · Surgery · First line $\cdot$ Recurrent disease

\section{Methodology}

During one and a half-day meeting, several topics on the management of ovarian cancer (OC) were reviewed by a panel of experts from GEICO about different areas. Each

\section{J. M. Del Campo}

Department of Medical Oncology, Vall d'Hebron University Hospital, Barcelona, Spain

\section{A. Cervantes}

Department of Hematology and Medical Oncology, Institute of Health Research INCLIVA, Hospital Clínico Universitario, University of Valencia, Valencia, Spain

Y. García

Department of Medical Oncology, Sabadell Hospital, Parc Taulí Healthcare Corporation, Sabadell, Barcelona, Spain

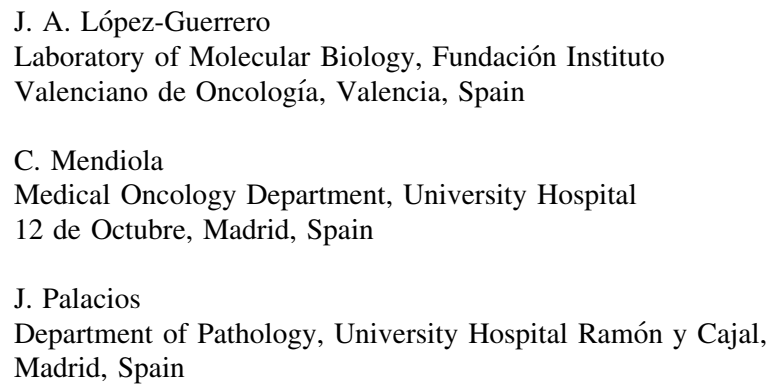


Table 1 Infectious Diseases Society of America-US Public Health Service Grading System for ranking recommendations in clinical guidelines [3]

\begin{tabular}{ll}
\hline $\begin{array}{l}\text { Category, } \\
\text { grade }\end{array}$ & Definition \\
\hline $\begin{array}{l}\text { Strength of recommendation } \\
\text { A }\end{array}$ & Good evidence to support a recommendation for use \\
B & Moderate evidence to support a recommendation for use \\
C & $\begin{array}{l}\text { Poor evidence to support a recommendation } \\
\text { D } \\
\text { Moderate evidence to support a recommendation against } \\
\text { use }\end{array}$ \\
Quality of evidence \\
I & $\begin{array}{l}\text { Evidence from } \geq 1 \text { properly randomized, controlled trial } \\
\text { II } \\
\text { Evidence from } \geq 1 \text { well-designed clinical trial, without } \\
\text { randomization; from cohort or case-controlled analytic } \\
\text { studies (preferably from }>1 \text { center); from multiple time } \\
\text { series; or from dramatic results from uncontrolled } \\
\text { experiments }\end{array}$ \\
III & $\begin{array}{l}\text { Evidence from opinions of respected authorities, } \\
\text { based on clinical experience, descriptive studies, } \\
\text { or reports of expert committees }\end{array}$
\end{tabular}

presentation covered the most accurate evidence about the specific topic and it was followed by a discussion in the panel of experts. The topics that were reviewed included: diagnosis, screening hereditary ovarian cancer, pathology, molecular biology, surgery of initial and advanced stages, systemic therapy of early and advanced stages, therapy of recurrent disease and strategies for the future in $\mathrm{OC}$ management.

To assign a level of evidence and a grade of recommendation to the different statements of this treatment guideline, it was decided to use the Infectious Diseases Society of America-US Public Health Service Grading System for ranking recommendations in clinical guidelines to determine the quality of evidence and strength of recommendation in each of the consensus recommendations (Table 1) [3].

When no unanimous consensus was achieved about the level of recommendation, an explanation of the different arguments was included in the manuscript.

Finally, a draft of the treatment guideline was sent to all the participants and also to other GEICO members for revision, discussion and final approval.

\section{J. Rubio}

Department of Medical Oncology, University Hospital Reina Sofía, Córdoba, Spain

\author{
A. Poveda Velasco \\ Department of Medical Oncology, Fundación Instituto \\ Valenciano de Oncología, Valencia, Spain
}

\section{Diagnosis}

Patients suspected to have adnexal mass

Transvaginal ultrasound (US) is considered the first-line imaging technique to be performed and includes morphology and color Doppler mapping. This will help determine its site of origin and characterize it as potentially benign or malignant. Transvaginal US has a high negative predictive value and is an excellent tool for ruling out OC [Quality of evidence, strength of recommendation: II, B] $[4,5]$.

CA 125, although not specific for EOC, is the most frequently used tumoral marker in the diagnostic process of an ovarian mass. It is elevated in $83 \%$ of women with EOC but in only $50 \%$ of those with stage I disease. In the presence of carcinomatosis, a proportion of CA 125/CEA $>25$ suggest ovarian cancer origin, and the opposite result, intestinal tumor. In young woman ( $<35$ years), additional tumor markers like inhibin, AFP or B-hCG, should be measured if clinically indicated $[3,6]$.

It has been suggested that serum HE4 and CA 125 along with the algorithm ROMA (risk of ovarian malignancy) may be useful for determining whether a pelvic mass is malignant or benign. Nevertheless, a recently published study found that subjective assessment by US performed better than the ROMA and RMI (risk of malignancy index) in discriminating malignant from benign masses [7].

\section{Patients with suspected ovarian cancer}

Surgical staging is the gold standard in OC and cannot be replaced by imaging techniques particularly in the detection of small peritoneal deposits. However, there is a trend toward increased use of imaging prior to surgical staging and cytoreduction to plan the surgical approach [8].

The staging accuracy of computed tomography (CT) or magnetic resonance imaging (MRI) is reported to be 70-90 \%, although few studies comparing the accuracy of both techniques are available. The accuracy of detection of peritoneal implants with both CT and MRI is dependent on their location, size and the presence of ascites. Contrastenhanced $\mathrm{CT}$ is the imaging modality of choice for staging of ovarian cancer, with the MRI being used as a problemsolving tool. In stages III and IV, the use of US is not recommended as staging modality due to its lower sensitivity to detect peritoneal metastases and other sites of disease compared to CT and MRI. CT can also be used to define disease extent that may help to evaluate the suitability for upfront cytoreductive surgery or for neoadjuvant chemotherapy. Although criteria for non-resectability vary widely between institutions and individual surgeons expertise, there are some preoperative imaging indicators, 
like the following: tumor deposits greater than $2 \mathrm{~cm}$ in the porta hepatis, diaphragmatic deposits, disease in the intersegmental fissure of the liver, lesser sac, small bowel mesentery and gastrosplenic ligament, parenchymal hepatic disease, and suprarenal aortic lymphadenopathy. However, this is highly dependent on the skills of the surgeon and the extension of the tumor. For instance, one solitary intraparenchymal liver metastasis can be potentially resected, and a diaphragmatic implant can be resected by well-trained surgeons. This fact and increasing surgical expertise in cytoreduction imply that preoperative CT predictors should be used with caution when assessing feasibility of primary cytoreduction [7].

Image-guided biopsy can be performed under US or CT guidance if, on the basis of imaging, the patient would benefit from neoadjuvant chemotherapy as histological confirmation of OC is mandatory. It is also essential prior to surgery if there is some clinical concern about the primary origin of the disease [7].

If there is uncertainty in the staging by radiological techniques, laparoscopic evaluation to select patients to cytoreductive surgery would play a great role in identifying patients unsuitable for optimal resection. Tissue for definitive histological diagnosis can also be obtained at the time of this procedure [III, B] [9].

Positron emission tomography using fluorodeoxyglucose (FDG-PET/CT) as staging tool in newly diagnosed advanced stages has not yet been fully determined. However, it provides an accurate assessment of disease in areas difficult to assess for metastases by CT and MRI like mediastinum, supraclavicular region, or small peritoneal implants. Normal-sized aortic lymph nodes with malignant involvement may also be identified by PET-CT [7].

Gastrointestinal (GI) workup in patients with diffuse carcinomatosis and GI symptoms may be indicated, including upper and/or lower endoscopy.

Since breast cancers can metastasize to the ovaries, more frequently when there is a bilateral involvement, mammography can help rule out this possibility and should be included in the preoperative workup for women older than 40 years who have not had one in the preceding 6-12 months.

Chest imaging, tumor markers, complete blood count and chemistry profile with liver and renal function are also part of the preoperative workup.

Screening/early detection of ovarian cancer

When the disease is detected early, the 5-year survival is in excess of $90 \%$ and this constitutes the rationale for the premise that detecting the disease in early stage may affect long-term survival. Although it has been shown that screening can detect the OC earlier and provide a survival benefit in the screening group, there is limited evidence that this can affect mortality from the disease and published data about it are conflicting [5].

In the largest trial UKTOCS using sequential CA 125 and transvaginal US, a survival advantage was achieved in the screened population compared with the control group. It was the consequence of a stage shift ( $82 \%$ of screendetected cancers were early stage compared with $34 \%$ of those from the control group, $p<0.0001)$. Final results of this study are awaited in 2015 before definitive conclusions can be drawn [10,11].

On the contrary, the PLCO study reported no mortality benefit with OC screening, although some concerns have been raised about trial design [12]. Despite the generalized belief that OC lacks obvious warning symptoms, a recent review of a large number of publications suggest that up to $90 \%$ of women experience symptoms before their diagnosis. A symptom index has been developed and when combined with CA 125 and HE4 showed an increase in specificity to $98 \%$.

Among high-risk women (mainly mutations in the BRCA1/2 genes), the sensitivity and effectiveness of screening are yet to be established. Several trials are still under way and their results will come out during the next years [13].

\section{Hereditary ovarian cancer}

Approximately $13 \%$ of EOCs are associated with inheritance of an autosomal dominant genetic aberration, which leads to cancer predisposition with a moderate to high penetrance [14]. BRCA1 and BRCA2 proteins are essential to the homologous recombination DNA repair mechanism, in recognizing double-strand breaks.

Currently, Dragon Database for Exploration of Ovarian Cancer Genes (DDOC) contains a set of 379 human genes experimentally verified as involved in OC [15]. Table 2 shows the best-known genes [16].

The estimated lifetime risk is 1 case in every 70 women, which is a $1.4 \%$ lifetime incidence [17]. This estimated lifetime risk increases to $3 \%$ in a second-degree relative, to $5 \%$ in a first-degree relative, and up to $9 \%$ in Lynch syndrome (hereditary nonpolyposis colorectal cancer). It reaches $39-60 \%$ in BRCA1 mutation and $11-30 \%$ in BRCA2 mutation [18].

Oncologists have a crucial opportunity to utilize risk assessment and cancer prevention strategies to interrupt the initiation or progression of $\mathrm{OC}$ in cancer survivors and individuals at high risk of developing cancer [19]. The Amsterdam II criteria [20] and Revised Bethesda Guidelines [21] (Table 3) can be used to identify the criteria for 
Table 2 Genes implicated in hereditary ovarian carcinoma

\begin{tabular}{ll}
\hline FA-BRCA pathway genes & HBOC \\
BRCA1 & \\
BRCA2 & Low penetrance genes \\
RAD51C & \\
RAD51D & \\
BRP1 & \\
BARD1 & \\
CHEK2 & \\
MRE1 1A & \\
NBN & \\
PALB2 & Lynch syndrome \\
RAD50 & \\
Mismatch repair genes & \\
MLH1 & \\
MSH2 & \\
MSH6 & \\
PMS2 & Li-Fraumeni syndrome \\
Other genes & \\
TP53 &
\end{tabular}

HBOC hereditary breast and ovarian cancer

referring a patient to the genetic counseling unit (GCU), based on three questions (Table 4). A detailed family history of cancer taken at the first visit with the oncology provider, and based on the following three questions, can raise the suspicion of a hereditary cancer syndrome and be referred to the GCU [II, A] [22].

Two hereditary syndromes, namely hereditary breast and ovarian cancer (HBOC) and Lynch syndrome, with mutations in BRCA1/2 genes and mismatch repair genes, respectively, have been identified (Table 5).

Hereditary nonpolyposis colorectal cancer (HNPCC) or Lynch syndrome is a common, autosomal dominant syndrome characterized by early onset (average age at onset $<45$ years), the development of neoplastic lesions in a variety of tissues (colon, gastrointestinal tract, ovary, and uterus) and microsatellite instability (MSI). For carriers of Lynch syndrome, the estimated lifetime risk of $\mathrm{OC}$ is 9-12\%.

HBOC is characterized by an increased susceptibility to breast cancer occurring at a young age, bilateral breast cancer, male breast cancer, and OC at any age. Other cancers such as prostate cancer, pancreatic cancer, gastrointestinal cancers, melanoma and laryngeal cancer occur more frequently in HBOC families. Hereditary site-specific breast cancer families are characterized by early-onset breast cancer with or without male cases, but without ovarian cancer. For this consensus, both will be referred collectively as hereditary breast and/or ovarian cancer. Germline mutations in the BRCA1 and BRCA2 genes are

Table 3 The Revised Bethesda Guidelines and Amsterdam II criteria [21, 25]

The Revised Bethesda Guidelines for testing colorectal tumors for microsatellite instability (MSI)

Tumors from individuals should be tested for MSI in the following situations:

1. Colorectal cancer diagnosed in a patient who is less than 50 years of age

2. Presence of synchronous, metachronous colorectal, or other HNPCC-associated tumors, ${ }^{\text {a }}$ regardless of age

3. Colorectal cancer with the MSI- $\mathrm{H}^{\mathrm{b}}$ histology ${ }^{\mathrm{c}}$ diagnosed in a patient who is less than 60 years of age ${ }^{\mathrm{d}}$

4. Colorectal cancer diagnosed in one or more first-degree relatives with an HNPCC-related tumor, with one of the cancers being diagnosed under age 50 years

5. Colorectal cancer diagnosed in two or more first- or second-degree relatives with HNPCC-related tumors, regardless of age

Amsterdam II Clinical criteria for families with Lynch syndrome

Each of the following criteria must be fulfilled:

3 or more relatives with an associated cancer (colorectal cancer, or cancer of the endometrium, small intestine, ureter or renal pelvis)

2 or more successive generations affected

1 or more relatives diagnosed before the age of 50 years

1 should be a first-degree relative of the other two

Familial adenomatous polyposis (FAP) should be excluded in cases of colorectal carcinoma

Tumors should be verified by pathologic examination

${ }^{a}$ Hereditary nonpolyposis colorectal cancer (HNPCC)-related tumors include colorectal, endometrial, stomach, ovarian, pancreas, ureter and renal pelvis, biliary tract, and brain (usually glioblastoma as seen in Turcot syndrome) tumors, sebaceous gland adenomas and keratoacanthomas in Muir-Torre syndrome, and carcinoma of the small bowel [26]

b MSI-H, microsatellite instability-high, in tumors refers to changes in two or more of the five National Cancer Institute recommended panels of microsatellite markers

c Presence of tumor infiltrating lymphocytes, Crohn's-like lymphocytic reaction, mucinous/signet-ring differentiation, or medullary growth pattern

d There was no consensus among the Workshop participants on whether to include the age criteria in guideline 3 above; participants voted to keep less than 60 years of age in the guidelines 
Table 4 Family history in three questions

Family history in three questions

1. How old was the diagnosis?

2. First-degree relatives

HBOC

LYNCH

3. Second-degree relative

HBOC hereditary breast and ovarian cancer

Table 5 Mutations in BRCA1/2 genes and mismatch repair genes in HBOC and Lynch syndrome

\begin{tabular}{lll}
\hline & HBOC & Lynch syndrome \\
\hline Genes & BRCA1 and & MLH1, MSH2, MSH6 and \\
& BRCA2 & PMS2 \\
$\begin{array}{c}\text { Increased } \\
\text { risk of } \\
\text { cancer }\end{array}$ & $\begin{array}{c}\text { Breast, ovarian, } \\
\text { pancreatic, } \\
\text { prostate }\end{array}$ & $\begin{array}{c}\text { Colon, uterine, ovarian, other } \\
\text { cancers of the digestive tract }\end{array}$ \\
\hline
\end{tabular}

HBOC hereditary breast and ovarian cancer

responsible for cancer susceptibility in the majority of HBOC families.

There is a high rate of tubal intraepithelial carcinoma (TIC) in high-risk women undergoing risk-reducing salpingo-oophorectomy. Recent studies have documented that up to $59 \%$ of high-grade pelvic (non-uterine) serous carcinomas are associated with serous TICs. This is consistent with the hypothesis that the fallopian tube is the source of a majority of these tumors [23]. Approximately $30 \%$ of women with fallopian tube cancer have a mutation in BRCA1 or BRCA2 $[24,25]$. In women with BRCA1 and BRCA2 mutations, the use of risk-reducing mastectomy was associated with a lower risk of breast cancer; riskreducing salpingo-oophorectomy was associated with a lower risk of breast and ovarian cancer [32].

Patients with invasive EOC with a germline mutation in BRCA1 or BRCA2 were associated with improved 5-year overall survival. BRCA2 carriers had the best prognosis. This may be due to distinct clinical behavior and/or to a better response to chemotherapy.

Primary prevention by detecting more women at high risk for the disease development by applying new methods of prevention like risk-reducing surgery is perhaps a more useful strategy for reducing mortality for OC patients. As mentioned before, there is accumulating evidence suggesting that serous neoplasia originates in secretory fallopian tube surface epithelium. This intraepithelial lesion has been found in about $43 \%$ of women with advanced serous cancers, so this finding may potentially serve as a carcinogenic marker. Its identification in women at uncertain risk by means of minimally invasive methods or with salpingectomy at the time of other major surgical procedures in women who have completed their childbearing may be a reasonable strategy that deserves investigation [26-28].

\section{Pathology and molecular genetics}

Several studies have shown that OC is not a single disease, but instead is composed of a diverse group of tumors that can be classified based on distinctive morphologic and molecular genetics features [29]. Additionally, the various subtypes have a different natural behavior and prognosis [33].

Based on light microscopy and molecular genetics, they can be subdivided into at least five main subtypes [30], classified by cell type into serous, mucinous, endometrioid, clear cell, and Brenner (transitional) tumors corresponding to different types of epithelia in the organs of the female reproductive tract. Once grouped by cell type, the tumors can be further subdivided into those that are clearly benign (cystadenomas), those that are clearly malignant (carcinomas), and those that have features somewhere between these two, variably called "atypical proliferative" tumors, tumors of "low malignant potential" or tumors of "borderline" malignancy. These subtypes show differences in epidemiological and genetic risk factors, precursor lesions, spreading patterns, molecular events during oncogenesis, response to chemotherapy and outcome.

Histopathological findings strongly suggest that there is a morphological and biological spectrum which starts with a benign serous cystadenoma/adenofibroma, and continues from a proliferative tumor (atypical proliferative serous tumor) to a non-invasive carcinoma (non-invasive micropapillary serous carcinomas), ending with an invasive lowgrade serous carcinoma (LGSC) (invasive micropapillary serous carcinomas). Type I tumors (low-grade serous carcinoma, mucinous carcinoma, endometrioid carcinoma, malignant Brenner tumor, and clear cell carcinoma) develop in a stepwise manner from well-recognized precursors, namely borderline tumors that in turn develop from cystadenomas and adenofibromas [31]. Type II tumors are high grade at presentation and are currently classified as high-grade serous carcinoma (HGSC), malignant mixed mesodermal tumors (carcinosarcomas), and undifferentiated carcinoma [32]. High-grade serous histology is more frequent in advanced stage. HGSC and LGSC have different histology, molecular genetic alterations and biology [33] (Table 6). HGSC displays TP53 mutations in over $90 \%$ of cases and rarely harbors the mutations that are found in the type I tumors (KRAS and BRAF). They are also characterized by potential aberrations in BRCA1 and BRCA2, in up to $50 \%$ of cases [34]. 
Table 6 High-grade serous carcinoma (HGSC) and low-grade serous carcinoma (LGSC) differences

\begin{tabular}{lll}
\hline & HGSC & LGSC \\
\hline $\begin{array}{l}\text { Risk factors } \\
\text { Precursor lesions }\end{array}$ & $\begin{array}{l}\text { BRCA 1/2 } \\
\text { Tubal intraepithelial } \\
\text { carcinoma } \\
\text { Pattern of spread } \\
\text { transcoelomic }\end{array}$ & $\begin{array}{c}\text { Serous borderline } \\
\text { tumor }\end{array}$ \\
$\begin{array}{l}\text { Molecular } \\
\text { abnormalities }\end{array}$ & BRCA, p53 & $\begin{array}{c}\text { Transcoelomic } \\
\text { spread }\end{array}$ \\
Ki-67 & BRAF, KRAS \\
Chemosensitivity & High & \\
Estrogen receptor & $2 / 3$ & Low \\
Prognosis & Poor & Intermediate \\
Median age at & Higher & $?$ \\
presentation & & Intermediate \\
\hline
\end{tabular}

Mucinous borderline tumors are classified into two different clinicopathological types: intestinal (85\% of cases) and endocervical $(15 \%)$. Bilateralism, in the case of a mucinous tumor, suggests that the possibility of adenocarcinoma metastasis, generally of gastrointestinal or pancreatic origin, should be ruled out. Moreover, bilateral ovarian tumors accompanied by pseudomyxoma peritonei tend to be of appendicular origin [35]. Immunohistochemical study with cytokeratin 7 and 20 can help in defining the origin of the lesion (EOC: CK7+/CK20-; metastasis: CK7-/CK20+).

Clear cell carcinomas (CCCs) constitute a spectrum of tumors of differing degrees of malignancy which are characterized by being formed by clear hobnailed, eosinophilic cells. Adenofibromas and clear cell borderline tumors are very uncommon. Given that CCCs frequently show a mixture of growth patterns and nuclear atypia, they are tumors that do not tend to progress from a histological point of view [36].

In CCCs, molecular alterations similar to those of EOCs have been described, but with a different frequency: betacatenin mutations (5\%), PTEN (5-8\%), K-RAS (15-30 \%), and MSI (5 \%) [37-39].

Ovarian clear cell and endometrioid carcinomas may stem from endometriosis. ARID1A mutations were observed in 55 of 119 ovarian CCCs (46\%), 10 of 33 endometrioid carcinomas (30\%), and none of 76 highgrade serous ovarian carcinomas [40].

Identifying patients who would benefit from particular targeted therapies is an important objective. The first step in developing tools to improve cancer control for OC is to recognize that OC represents many diseases [41]. Additionally, it is highly recommended that human biospecimens for translational studies be available from clinical trials.

\section{Surgical treatment}

Surgery is the cornerstone in treatment of ovarian cancer. All patients with newly diagnosed disease who are fit for surgery should be considered for a full staging laparotomy for accurate information on disease and histology. This is important for predicting prognosis and decision of postsurgical therapy. Based on published improved outcomes, it is recommended that a gynecologic oncologist surgeon perform the primary surgery [II, A] [42]. Types of surgery for OC may include: primary surgery for staging and cytoreduction, interval debulking surgery (IDS); secondary cytoreduction, second look operation, and palliative surgery.

Early disease (clinical stage I/II)

The aim was proper staging of disease and removal of all macroscopic tumor. Surgery can be performed either preferably by laparotomy, which is the most accepted procedure, or minimally invasive surgery in selected patients if performed by an experienced gynecologic oncologist. Procedures must comprise thorough inspection and palpation of all peritoneal surface, total hysterectomy and bilateral salpingo-oophorectomy ( $\mathrm{TH}+\mathrm{BSO}$ ), omentectomy, pelvic and bilateral aortic lymphadenectomy up to the renal vessels, biopsies of pelvic peritoneum, paracolic gutters and right subdiaphragmatic area, sampling of ascites or peritoneal washing for cytology (when no ascites is found). Appendectomy is recommended in mucinous tumors [43].

Several updated studies have concluded that completeness of surgical staging in patients with early stage was significantly associated with better outcomes. The 2010 GCIG consensus stated that surgical staging should be mandatory and be performed by a gynecologic oncologist [II, A] [2]. Under-staged patients in previous surgery should be re-staged according to the same surgical principles mentioned above. The same principle should be applied for patients with poorly differentiated tumor, clear cell histology, and stage IC due to ovarian surface involvement [44].

For a young patient ( $<40$ years) who wishes to maintain fertility, a unilateral salpingo-oophorectomy may be adequate for selected stage I tumors (Ia and Ic due to intraoperative rupture but with negative cytology, grade 1 or 2 , but not stage IB) in addition to the staging procedure. After fulfilling their wishes of fertility, salpingo-oophorectomy is recommended [III, B]. The practice of carrying out a wedge biopsy on a grossly normal contralateral ovary should be discouraged. If the histology is of endometrioid type, an endometrial biopsy should be performed to rule out a concurrent endometrial cancer. Most studies have 
found that conservative treatment is suitable for patients with serous, mucinous, or endometrioid carcinoma but not for patients with high-risk factors such as clear cell or poorly differentiated carcinoma $[45,46]$.

\section{Advanced disease (III-IV)}

The standard treatment of advanced OC is cytoreductive surgery followed by platinum-based combination chemotherapy. Although the ultimate goal is cytoreduction to microscopic disease by removing all visible disease, successful cytoreduction to small-volume disease $(<1 \mathrm{~cm})$ increases the frequency of complete response and overall survival [II, A] [47-49]. According to the 2010 OC Consensus conference held in Vancouver, the term "optimal" cytoreduction should be reserved for those with no macroscopic residual disease [2].

The maximal surgical effort may comprise sometimes the following procedures: TAH + BSO (supracervical hysterectomy is also appropriate in some circumstances), omentectomy, radical pelvic dissection, bowel resection, diaphragm or other peritoneal surface stripping, splenectomy, partial hepatectomy, partial gastrectomy or cystectomy, distal pancreatectomy, or lymphadenectomy (bulky or suspicious lymph nodes resection). If complete cytoreduction is achieved, lymphadenectomy may increase overall survival [55].

Some contraindications for the outcome of this "maximum" effort surgery have been pointed out such as the following: poor performance status (Karnofsky <40), mesentery root involvement, extra-abdominal visceral disease, multiple intraparenchymal liver metastases, or intestinal massive-serosal carcinomatosis [II, A]. Nevertheless, as surgery on advanced OC evolves, some of these contraindications are being overcome $[50,51]$.

Delayed primary surgery after neoadjuvant chemotherapy or IDS is an option for selected patients with stage IIIC and IV. Despite the results of a recent randomized controlled trial, this therapeutical plan remains controversial. According to some authors, neoadjuvant chemotherapy followed by IDS should be reserved for patients who do not have access to gynecologic or surgical oncologist, cannot tolerate the procedure, and/or for whom optimal cytoreduction is deemed not feasible by an experienced surgical team. The goal of this surgery should be the same as in primary surgery and comprise the same procedures if necessary $[52,56]$.

Patients with low volume $(<1 \mathrm{~cm})$ of residual disease after upfront primary debulking surgery are potential candidates for intraperitoneal (IP) chemotherapy and, in these patients, consideration should be given to placement of an IP catheter with initial surgery [53].

\section{Systemic therapy in first line}

Early stages

The results of studies published in the last 10 years support adjuvant treatment with chemotherapy after surgery in most patients showing early stages of epithelial ovarian cancer [54-58]. Only low-risk patients (stages IA/B Grade 1 and no clear cell histology) with correct surgical staging require observation exclusively, as long-term survival after surgery is above $90 \%$ [59].

Adjuvant treatment with chemotherapy after surgery is indicated in high-risk early stages (IA and IB Grade 3, clear cell tumors and any grade of stages IC and IIA) [I, A]. However, there is no consensus on the need to treat stages IA/B Grade 2. For these cases, both observation and adjuvant treatment can be regarded as valid options (Fig. 1) [1]. The ICON 1 [62] and ACTION [60] studies, as well as the combined analysis of both [61], support the use of adjuvant chemotherapy in early stages with a high risk of
Fig. 1 Adjuvant therapy in stage I and stage IIA epithelial ovarian cancer

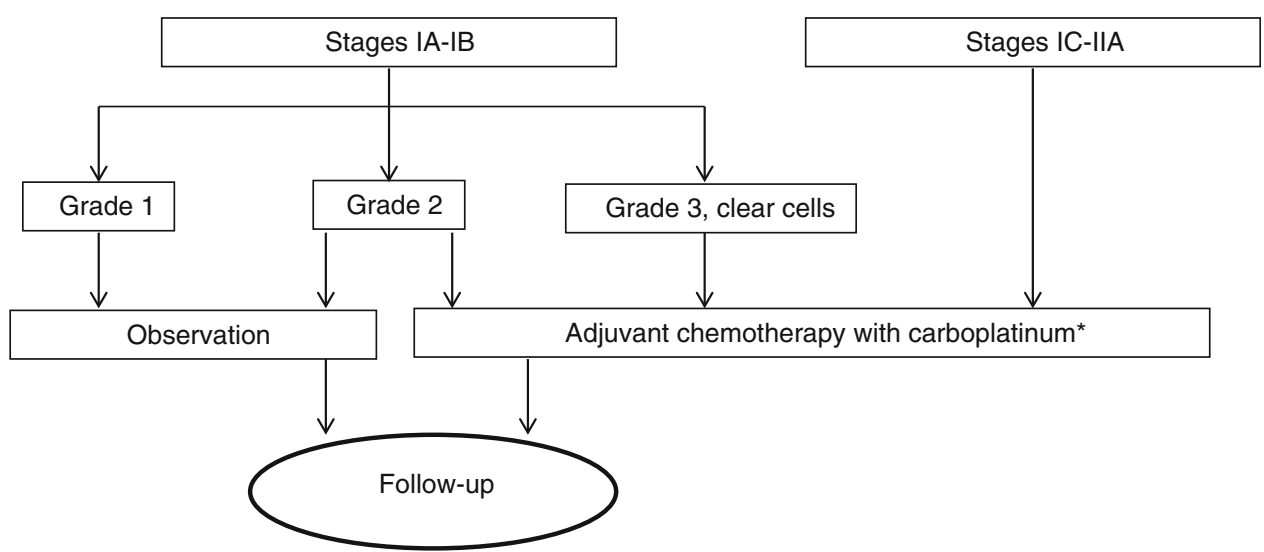


relapse, as an improvement is seen in both disease-free survival and overall survival (OS) when adjuvant platinumbased chemotherapy is given.

As yet, there are no data from comparative studies on these stages to determine the value of adding paclitaxel to platinum. Chemotherapy must at least include carboplatinum (AUC 5-7.5). The GOG-157 trial compared the administration of 3 cycles of paclitaxel $\left(175 \mathrm{mg} / \mathrm{m}^{2}\right.$ over $3 \mathrm{~h}$ ) and carboplatin (AUC 7.5) versus 6 cycles of the same combination in patients with stage I optimally staged. The risk of recurrence was $33 \%$ lower for patients treated with 6 cycles. However, this difference did not reach statistical significance (95\% CI 0.49-1.16). Additionally, the 6-cycle arm was associated to a higher hematological toxicity and neurological grade $2-4$ toxicity ( 28 vs. $13 \%$ ). Based on this trial, the current standard chemotherapy in the adjuvant setting consists of at least 3 cycles of paclitaxel and carboplatin [64].

\section{Advanced stages}

\section{Conventional chemotherapy}

The current therapeutic strategy generally recommended for the treatment of advanced OC (IIc-IV) is optimal cytoreductive surgery followed by 6 cycles of paclitaxel and carboplatin [61-63]. The recommendation to include paclitaxel with platinum was based on two large randomized studies that established the superiority of the paclitaxelcisplatin combination versus cyclophosphamide-cisplatin $[64,65]$. Mature data maintain this results [70], and the combined analysis showed survival benefits with the paclitaxel scheme [66]. Subsequently, three randomized studies that included over 1,500 patients compared paclitaxelcisplatin with paclitaxel-carboplatin; no differences were found in response to progression-free survival (PFS), but toxicity and tolerability profiles were better for the carboplatin-combination arms [67-69]. According to the 4th Ovarian Cancer Consensus Conference [2], the standard treatment should include paclitaxel $\left(175 \mathrm{mg} / \mathrm{m}^{2}\right)$ and carboplatin (AUC 5-7.5) every 3 weeks for 6 cycles [I, A]. The data from the MITO-2 randomized, multicenter clinical trial conducted by the Multicenter Italian Trials in Ovarian (MITO) Cancer group indicate that the activity of carboplatin and pegylated liposomal doxorubicin (PLD) is similar to that of standard first-line therapy with carboplatin/paclitaxel in advanced ovarian cancer. Moreover, in terms of safety, the study group had a lower incidence of peripheral neuropathy $(15 \%)$ and alopecia $(14 \%)$ than the control group (47 and $63 \%$, respectively) [70]. However, this was a study with a design of superiority that did not meet its primary endpoint. For this reason, it should be considered a negative study that has not changed the standard of care. However, it can be considered a treatment option for patients not eligible to receive taxol.

\section{Triplet and doublet chemotherapies}

Various treatment strategies have been applied with a view to improving the prognosis of these patients. One is the addition of one or more drugs without cross resistance with the therapy which up to now has been considered standard (carboplatin-paclitaxel). Three studies have been published in this area evaluating the addition of a third drug in triple or sequential form (epirubicin, gemcitabine, topotecan or PLD) [71-73].

Unfortunately, none has been shown to be of any advantage. Adding one or more drugs only signifies greater toxicity. The administration of a third or more drugs is not therefore recommended at present [I, E].

\section{Maintenance chemotherapy}

In an effort to improve the modest results obtained in patients with suboptimal debulking, trials have been conducted with consolidation or maintenance chemotherapy. To date, none of the treatments administered following initial induction with platinum/paclitaxel have shown to improve survival [74-78].

\section{Neoadjuvant chemotherapy (NAC)}

A meta-analysis examined the effectiveness of NAC with platinum and IDS for advanced ovarian cancer, including 835 patients from 51 studies. Patients who had undergone IDS after an attempt at primary surgery were found to have survived for less time than those who had primary surgery. However, the review only included phases I to II and retrospective studies [79]. This observation was the background for a study conducted by the European Organisation for the Research and Treatment of Cancer (EORTC) Gynaecological Cancer Group, in conjunction with the National Cancer Institute of Canada (NCIC) Clinical Trials Group (EORTC-55971) between 1998 and 2006 that included 670 women with stages IIIC or IV ovarian cancer [80]. The women were randomized to primary debulking surgery, followed by at least six cycles of platinum-based chemotherapy or three cycles of NAC, also platinum based, followed by IDS, and by at least three more cycles of platinum-based chemotherapy. The median OS after primary debulking surgery was 29 months, compared to 30 months for the patients assigned to NAC. The hazard ratio for death in the group assigned to NAC followed by interval debulking, as compared with the group assigned to primary debulking surgery followed by chemotherapy, was 0.98 . The subgroup of patients who had optimal debulking 
$(<1 \mathrm{~cm})$ after primary debulking surgery or NAC followed by IDS had the best median OS [92].

Despite these results, NAC is still a controversial issue. Some concerns have risen from the quality of the surgery performed in this trial and the wide use of NAC even in patient candidate for optimal upfront debulking surgery. In conclusion, NAC should be reserved for those who cannot tolerate PDS and/or for whom optimal cytoreduction is not feasible after an adequate evaluation performed by a surgical team well trained on cytoreduction [I, B] [59].

\section{Dose-dense regimen}

A Japanese study evaluated the weekly (dose-dense) administration of paclitaxel in patients with advanced ovarian cancer. This was a phase III study which included 631 patients with stage II-IV (82\% were stage III-IV) [81]. They were randomized to receive paclitaxel every 3 weeks at the dose of $185 \mathrm{mg} / \mathrm{m}^{2}$ versus weekly paclitaxel (dose-dense regimen) at $80 \mathrm{mg} / \mathrm{m}^{2}$ for 3 weeks. Both arms received carboplatin at an AUC of 6 every 3 weeks. According to the published results, there was a statistically significant improvement in PFS (28 vs. 17.2 months, $p=0.015$ ) in favor of the dose-dense administration arm. After long-term follow-up, at 6.4 years of median, it continues to show a highly statistically significant improvement in median PFS in favor of the dd-TC group compared with the c-TC group [28.1 vs. 17.5 months, hazard ratio (HR) $0.75,95 \%$ CI $0.62-0.91, p=0.0037]$, and also a benefit in the 5-year overall survival rate $(58.7$ vs. 51.1 \%, HR 0.79, $95 \%$ CI 0.63-0.99) [82] [I, B]. This interesting strategy should be confirmed in the Caucasian population, as the Japanese population may have genetic differences that could influence the pharmacokinetics or pharmacodynamics of the weekly schedule. In fact, toxicity in the Japanese population was significant with $36 \%$ of patients discontinuing therapy due to side effects. Two European trials are dealing with this topic, MITO 7 and ICON 8, however, they have not been presented and we do not have definitive data for a formal recommendation of this schedule to Caucasian patients with advanced ovarian cancer.

\section{Intraperitoneal chemotherapy (IP CT)}

IP chemotherapy has certain clinical and pharmacological advantages over intravenous chemotherapy in patients with EOC limited to the abdominal cavity, who have had optimal debulking surgery. Three large randomized studies found improvements in PFS and OS (Table 7) [83, 84, 93].

The last and most important of them was the GOG-172 study, published in 2006 by Dr. Armstrong [85] that included 415 patients with stage III and residual tumor $\leq 1 \mathrm{~cm}$. The patients were randomized to receive either cisplatin $75 \mathrm{mg} / \mathrm{m}^{2}$ i.v. plus paclitaxel $135 \mathrm{mg} / \mathrm{m}^{2}$ i.v. by continuous infusion over $24 \mathrm{~h}$ every 3 weeks for 6 cycles or paclitaxel $135 \mathrm{mg} / \mathrm{m}^{2}$ i.v. followed by cisplatin $100 \mathrm{mg} /$ $\mathrm{m}^{2}$ i.p. plus paclitaxel $60 \mathrm{mg} / \mathrm{m}^{2}$ i.p. on day 8 every 3 weeks for 6 cycles. As with the previous study, patients in the IP CT arm had longer PFS (23.8 vs. 18.3 months, $p=0.05)$ and OS (65.6 vs. 49.7 months, $p=0.03$ ).

A number of meta-analyses and systematic reviews have analyzed the above studies together and have categorically confirmed the results in terms of benefits over PFS and OS. However, what they also show is an increase in toxicity, especially fever, fatigue, gastrointestinal problems, infection, pain, deafness and metabolic and neurological abnormalities [86].

IP CT has therefore shown to be superior to i.v. CT and is another standard option in the management of patients with stage III and residual tumor $\leq 1 \mathrm{~cm}$, even taking into account the technical issues with this method and the toxicity which at present limits its routine use [I, A]. Because of these difficulties, IP CT may be an option only for selected patients and selected centers.

\section{Antiangiogenic therapy}

Two phase III trials (GOG 0218 and ICON7) [87, 88] have shown that bevacizumab may be beneficial when added to

Table 7 Summary of studies in intraperitoneal chemotherapy

\begin{tabular}{|c|c|c|c|c|}
\hline Study & Control regimen & Experimental regimen & $\begin{array}{l}\text { Eligible } \\
\text { patients }\end{array}$ & $\begin{array}{l}\text { No. of } \\
\text { patients }\end{array}$ \\
\hline $\begin{array}{l}\text { SWOG } 8501 / \text { GOG } \\
\text { 104, Alberts et al. } \\
{[83]}\end{array}$ & $\begin{array}{l}\text { Cisplatin, } 100 \mathrm{mg} / \mathrm{m}^{2} \text { i.v.; } \\
\text { cyclophosphamide, } 600 \mathrm{mg} / \mathrm{m}^{2} \text { i.v. } \\
\text { q } 3 \text { weeks } \times 6\end{array}$ & $\begin{array}{l}\text { Cisplatin. } 100 \mathrm{mg} / \mathrm{m}^{2} \text { i.p.; cyclophosphamide, } 600 \mathrm{mg} / \\
\mathrm{m}^{2} \text { i.v. q } 3 \text { weeks } \times 6\end{array}$ & $\begin{array}{l}\text { Stage III, } \\
\leq 2 \mathrm{~cm} \\
\text { residual }\end{array}$ & 546 \\
\hline $\begin{array}{l}\text { GOG 114/SWOG } \\
\text { 9227, Markman } \\
\text { et al. [84] }\end{array}$ & $\begin{array}{l}\text { Cisplatin. } 75 \mathrm{mg} / \mathrm{m}^{2} \text { i.v.; paclitaxel, } \\
135 \mathrm{mg} / \mathrm{m}^{2} 24 \text {-h i.v. } \mathrm{q} 3 \text { weeks } \times 6\end{array}$ & $\begin{array}{l}\text { Carboplatin, AUC } 9 \text { i.v. q } 28 \text { days } \times 2 \text {; cisplatin, } \\
100 \mathrm{mg} / \mathrm{m}^{2} \text { i.p.; paclitaxel, } 135 \mathrm{mg} / \mathrm{m}^{2} 24 \text { h i.v. } \mathrm{q} \\
3 \text { weeks } \times 6\end{array}$ & $\begin{array}{l}\text { Stage } \mathrm{III}, \\
\leq 1 \mathrm{~cm} \\
\text { residual }\end{array}$ & 462 \\
\hline $\begin{array}{l}\text { GOG 172, Armstrong } \\
\text { et al. [85] }\end{array}$ & $\begin{array}{l}\text { Cisplatin, } 75 \mathrm{mg} / \mathrm{m}^{2} \text { i.v.; paclitaxel, } \\
135 \mathrm{mg} / \mathrm{m}^{2} 24 \text { h i.v. q } 3 \text { weeks } \times 6\end{array}$ & $\begin{array}{l}\text { Paclitaxel, } 135 \mathrm{mg} / \mathrm{m}^{2} \text { 24-h i.v.; Cisplatin, } 100 \mathrm{mg} / \mathrm{m}^{2} \\
\text { i.p.; paclitaxel, } 60 \mathrm{mg} / \mathrm{m}^{2} \text { i.p. on day } 8 \mathrm{q} \\
3 \text { weeks } \times 6\end{array}$ & $\begin{array}{l}\text { Stage III, } \\
\quad \leq 1 \mathrm{~cm} \\
\text { residual }\end{array}$ & 415 \\
\hline
\end{tabular}


standard chemotherapy with paclitaxel and carboplatin in the first-line treatment of ovarian cancer.

Although both trials explored the same concept, there were some differences in the design of the studies that it is worth to be explained. The GOG-218 was a randomized double blinded trial comparing bevacizumab with placebo in three different arms: control arm with placebo during chemotherapy followed by a maintenance phase with placebo, initiation group with bevacizumab added to chemotherapy followed by placebo and the throughout group with bevacizumab added to initial chemotherapy followed by a limited period of maintenance with bevacizumab. In the ICON-7, the design was simpler, without placebo and with only two arms, a control group with paclitaxel and carboplatin and the experimental arm with bevacizumab added to paclitaxel-carboplatin followed by a maintenance period with bevacizumab. There were also differences in the duration of bevacizumab (15 months in GOG-218 vs. 12 months in ICON-7), the dose (15 mg/kg in GOG-218 vs. $7.5 \mathrm{mg} / \mathrm{kg}$ in ICON 7) and the population of patients included (FIGO stage III-IV with macroscopic residual disease after surgery in GOG-218 vs. FIGO stage I of high risk to stage IV in ICON-7).

Both trials met their primary endpoint. In the COG-218, the administration of bevacizumab concurrently with chemotherapy followed by a maintenance phase of bevacizumab was associated with a significant increment in the median PFS from 10.3 to 14.1 months (HR $0.71,95 \%$ CI $0.625-0.824, p<0.001)$. In the ICON-7, the median PFS was 17.3 months in the standard-therapy group and 19.0 months in the bevacizumab group (HR $0.81,95 \% \mathrm{CI}$ $0.70-0.94, p=0.004$ ).

Regarding tolerability, the main toxicity associated to the administration of bevacizumab was hypertension, which was grade 2 or higher in 22.9 and $18.9 \%$ of patients in the GOG-218 and ICON-7 trial, respectively. Moreover, there were no significant differences in the rates of other adverse events, including gastrointestinal perforation or fistula, proteinuria of grade 3 or greater, neutropenia of grade 4 or greater or febrile neutropenia, venous or arterial thrombosis, and wound disruption.

Some additional exploratory analysis of both trials has shown the following data:

1. A sensitive analysis of the GOG-218 censoring progression by CA 125 and considering only the patients who progressed by radiological imaging showed that the median PFS was 12.0 months in the control group but 18.0 months in the bevacizumabthroughout group (HR 0.645, $95 \%$ CI $0.551-0.756$, $p<0.001$ ).

2. The test for interaction performed in the ICON-7 suggests that the size of the effect of bevacizumab differed between patients at high risk for progression and the rest of the study population $(p=0.06)$. A subanalysis of patients at high risk of progression defined by stage IV or stage III and suboptimal cytoreduction with residual disease $>1 \mathrm{~cm}$ showed that the estimated median PFS was 10.5 months with standard therapy, as compared with 16 months with bevacizumab (HR $0.73,95 \%$ CI $0.60-0.93 ; p=0.002$ ).

3. In a preliminary overall survival analysis of the ICON7 requested by regulatory agencies (the number of events is not yet enough for this kind of analysis), it was showed a HR for death in the bevacizumab group of 0.85 (95\% CI 0.69-1.04, $p=0.11$ ). However, the test for interaction suggests that the size of the effect of bevacizumab on overall survival differs between the
Fig. 2 First-line systemic treatment options in advanced ovarian cancer

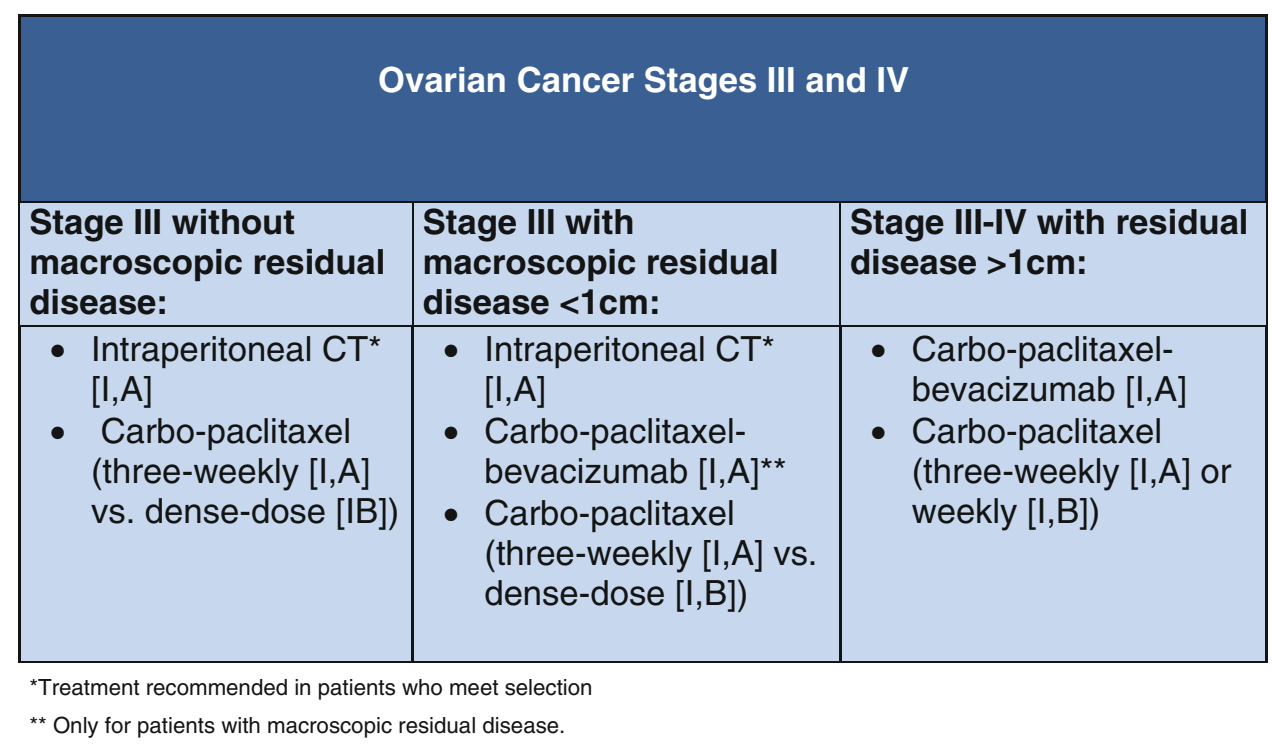


patients at high risk for progression and the rest of the women studied $(p=0.011)$. Among the women at high risk for progression, the median overall survival was 28.8 months in the standard-therapy group and 36.6 months in the bevacizumab group (HR 0.64, $95 \%$ CI $0.48-0.85, p=0.002$ ).

Based on the available data, bevacizumab added to initial chemotherapy followed by a maintenance period of bevacizumab should be deserved for patients who, following standard surgery, are found to have macroscopic residual disease [I, A]. According to exploratory analysis, the benefit seems to be more significant in patients with either stage III disease and residual disease $>1 \mathrm{~cm}$, or stage IV disease.

Figure 2 shows the first-line systemic treatment options in advanced ovarian cancer.

\section{Therapy for relapsed ovarian cancer}

Approximately 70-80\% of patients diagnosed with EOC will suffer a relapse after receiving first-line chemotherapy based on platinum and taxane. According to the Second Consensus on OC held in 1998, a relapse was defined by the presence of at least two of the following criteria [1]:

- Symptoms that may suggest disease (abdominal pain, distension, etc.).
- Clinical or radiological evidence of disease.

- Progressive rise in CA 125 , doubly confirmed by GCIG criteria.

A trial by the Medical Research Council and European Organisation for Research and Treatment of Cancer (MRCOV05) examined the consequences of early institution of treatment for recurrence based exclusively on CA 125 criteria of progression versus treatment delayed until clinical symptoms appeared [89]. The study concluded that there was no survival benefit in the treatment of recurrent OC based exclusively on a rise in the CA 125 , and that it anticipates a deterioration in the quality of life [I, A]. In the last Ovarian Cancer Consensus Conference (OCCC), a new classification of recurrent patients was proposed. Distinct patient populations for clinical trial enrolment may be considered according to interval from last platinum therapy. Progression-free interval (PFI) is defined from the last day of platinum until disease progression. The following subgroups should be considered:

- Progression while receiving last line of platinum-based therapy or within 4 weeks of last platinum dose.

- PFI since last line of platinum of $<6$ months.

- PFI since last line of platinum of 6-12 months.

- PFI since last line of platinum of $>12$ months.

The authors of this guideline strongly support the use of the classification proposed in the OCCC.
Fig. 3 Treatment options in relapsed ovarian cancer. (Defined by Progression FreeInterval)

\begin{tabular}{|c|c|c|}
\hline \multicolumn{3}{|c|}{$\begin{array}{l}\text { Treatment of Distinct Sub-groups } \\
\text { (Defined by Progression Free-Interval) }\end{array}$} \\
\hline $\begin{array}{l}\text { PFI < } 6 \text { m } \\
\text { - MONOTHERAPY } \\
\text { [IA]: PDL, Weekly } \\
\text { Placlitaxel, } \\
\text { Gemcitabine, } \\
\text { Topotecan. } \\
\text { - Single agent } \\
\text { chemotherapy } \\
\text { (weekly paclitaxel, } \\
\text { PLD, topotecan) + } \\
\text { bevacizumab [I,A]. }\end{array}$ & $\begin{array}{l}\text { PFI 6-12 m. } \\
\text { - Combination } \\
\text { without platinum: } \\
\text { Trabectedin + PDL } \\
{[\text { I,A]. }} \\
\text { - Combi with } \\
\text { platinum: } \\
\text { Carbo + PDL [I,A] } \\
\text { Carbo + GEM [I,A] } \\
\text { Carbo + PAC [I,B] } \\
\text { - Carbo + GEM + } \\
\text { Bevacizumab [I,A] } \\
\text { - Monotherapy }\end{array}$ & $\begin{array}{ll}\text { PFI > } 12 \text { m. } \\
\text { - } \\
\text { Evaluate for surgery } \\
\text { [II,A]. } \\
\text { Combination with } \\
\text { platinum [I,A]: } \\
\text { Carbo + PLD } \\
\text { Carbo + GEM } \\
\text { Carbo + PAC } \\
\text { Carbo + GEM + } \\
\text { Bevacizumab [IA] } \\
\text { Trabectedin + PLD if } \\
\text { carbo alergy [I,A]. }\end{array}$ \\
\hline \multicolumn{3}{|c|}{$\begin{array}{l}\text { * A non platinum-based combination with trabectedine and PLD was studied in the OV-301 trial showing this } \\
\text { combination to be superior to single agent PLD in the first recurrence of ovarian cancer. The benefit was restricted to } \\
\text { patients with a platinum-free interval (PFI) }>6 \text { months, specially in those considered partially platinum-sensitive (PFI 6- } \\
12 \text { months). } \\
\text { * * In patients not suitable for combination chemotherapy. Pegylated liposomal doxorubicin(PLD), Carboplatin (Carbo), } \\
\text { Gemcitabine (GEM), Paclitaxel (PAC). }\end{array}$} \\
\hline
\end{tabular}


Treatment of distinct subgroups defined by PFI

Secondary cytoreduction may be appropriate in selected patients despite there is no level 1 evidence which demonstrates a survival advantage. The goal of this surgery is the same as in primary upfront primary surgery. Best candidates for the survival benefit of this surgery are those with a long interval of disease free, no ascites at recurrence, localized disease or few sites of tumor, and complete resection of disease.

For the majority of patients with recurrent EOC, the treatment is based only on systemic therapy. Several factors should be considered in the selection of second-line therapy in EOC:

- Factors depending on the treatment:

- Response to the last therapy and time since it finished

- Activity and toxicity of available treatments

- Ease of administration and cost.

- Factors depending on the patient:

- Previous and residual toxicity experienced by the patient

- Clinical condition and previous medical history

- Preference of the patient.

Figure 3 shows treatment of distinct sub-groups (defined by PFI).

\section{Treatment of patients with a PFI $<6$ months}

Patients with platinum-resistant relapse used to be candidates for inclusion in clinical trials with new agents. In the absence of a clinical trial, single-agent therapy without "platinum" is the best palliative option. Several drugs have shown, in phase III trials, some activity with response rates (RR) of 10-15\% and median overall survival (OS) of
9-12 months. Some studies have found combination chemotherapy to be active in patients with a relapse after a PFI $<6$ months [1]. However, all these studies show that chemotherapy combinations do not improve PFS or OS, but constantly toxicity is significantly higher.

According to these data, in patients with Recurrent OC and a PFI $<6$ months, sequential single-agent therapy is the best palliative option as quality of life is the most important endpoint [I, A]. A randomized phase III trial evaluating bevacizumab $15 \mathrm{mg} / \mathrm{kg}$ every 3 weeks plus chemotherapy versus chemotherapy for platinum-resistant recurrent ovarian cancer [90], provides statistically significant and clinically meaningful improvement in PFS (3.4 vs. 6.7 months), HR $0.48(0.38-0.60)$ and objective response rate (ORR) versus chemotherapy alone (30.9 vs. $12.6 \%$ ). Strict inclusion criteria minimized the incidence of bevacizumab adverse effects. This is the first phase III trial in platinum-resistant OC to show benefit with a targeted therapy and improved outcome with a combination versus monotherapy [90] [I, A].

\section{Treatment of patients with a PFI >12 months}

Patients with recurrent disease and a PFI over 12 months are considered fully platinum sensitive, as they use to respond to retreatment with a platinum-based regimen. We have strong evidence, summarized in the Table 8 , showing that a platinum-based combination is associated to a longer PFS and also OS in comparison to single-agent platinum chemotherapy [I, A]. As there is no combination that can be considered superior in terms of efficacy, the selection between the different options should be based on the toxicity profile of the different options. Table 8 also summarizes the most relevant toxicities with each combination [91-94].

Hypersensitivity can occur during the second-line treatment. This may occur in up to $25 \%$ of patients; it is

Table 8 Recurrent OC PFI $>12$ months, two (with platinum) are better than one

\begin{tabular}{|c|c|c|c|c|c|c|c|c|}
\hline Study & $N$ & $\begin{array}{l}\text { Prior } \\
\text { taxane }(\%)\end{array}$ & 6-12 Months $(\%)^{\mathrm{a}}$ & Treatment & PFS & HR & $95 \% \mathrm{CI}$ & OS \\
\hline ICON 4 [91] & 802 & 43 & 25 & $\begin{array}{l}\text { Carboplatin } \\
\text { Carboplatin-Pac }\end{array}$ & $\begin{array}{l}9 \text { months } \\
12 \text { months }\end{array}$ & 0.76 & $0.66-0.89$ & $\begin{array}{l}24 \text { months } \\
29 \text { months }\end{array}$ \\
\hline GEICO 9801 [92] & 81 & 87.20 & 42.30 & $\begin{array}{l}\text { Carboplatin } \\
\text { Carboplatin-Pac }\end{array}$ & $\begin{array}{l}8.4 \text { months } \\
12.2 \text { months }\end{array}$ & 0.54 & $0.32-0.92$ & $\begin{array}{l}17 \text { months } \\
-\end{array}$ \\
\hline AGO-EORTC [93] & 356 & 70 & 40 & $\begin{array}{l}\text { Carboplatin } \\
\text { Carboplatin-Gem }\end{array}$ & $\begin{array}{l}5.8 \text { months } \\
8.6 \text { months }\end{array}$ & 0.72 & $0.58-0.90$ & $\begin{array}{l}17.3 \text { months } \\
18 \text { months }\end{array}$ \\
\hline CALYPSO [94] & 973 & 35 & 99 & $\begin{array}{l}\text { Carboplatin-Pac } \\
\text { Carboplatin-PLD }\end{array}$ & $\begin{array}{l}9.4 \text { months } \\
11.3 \text { months }\end{array}$ & 0.821 & $0.72-0.94$ & - \\
\hline
\end{tabular}

${ }^{a}$ Rate of patients with a platinum-free interval of 6-12 months

$P F S$ progression-free survival, $O S$ overall survival, $H R$ hazard ratio, $95 \% C I 95 \%$ confidence interval 
more likely with carboplatin and usually appears from the seventh treatment cycle. Reactions may be mild (skin rash) but sometimes are severe (anaphylactic shock). The reintroduction of the drug will depend on the expected benefits weighed against the potential risks. In such a case, one of the desensitizing protocols published in the literature should be followed [1].

A randomized trial of carboplatin-gemcitabine plus bevacizumab or placebo included 484 patients with a recurrent ovarian cancer over 6 months after first line of platinum-based chemotherapy [95]. Patients included should have measurable disease and the primary endpoint was PFS as determined by RECIST progression. The association of bevacizumab increased the median PFS from 8.4 to 12.4 months (HR $0.48,95 \%$ CI 0.34-0.60) and was confirmed by an independent radiology committee. Additionally, the response rate was also higher (78.5 vs. $57.4 \%$, $p<0.0001)$. The third pre-planned analysis of overall survival has not shown significant differences (33.4 with bevacizumab vs. 33.7 with placebo), and it has been explained more probably for the long post-progression time and the significant number of chemotherapy lines given during this period. On the basis of these results, bevacizumab was approved for the platinum-sensitive recurrent ovarian cancer by the EMA (European Medicines Agency).

\section{Treatment of patients with a PFI 6-12 months}

Patients relapsing between 6 and 12 months after the last platinum-based chemotherapy used to have a lower response to platinum than those considered fully platinum sensitive (PFI $>12$ months) and also a shorter PFS and OS. For this reason, different strategies beyond carboplatinbased regimens are under investigation on this group of patients.

One of these strategies is the use of non-platinum-based regimen, based on the results of the OVA-301 trial [96]. This multinational, multicenter trial assessed the safety and efficacy of trabectedin plus PLD versus PLD alone in platinum-sensitive and platinum-resistant patients with recurrent ovarian cancer. The primary endpoint was PFS. Patients were randomly assigned to receive a 90-min infusion of PLD $50 \mathrm{mg} / \mathrm{m}^{2}$ every 4 weeks $(n=330)$ or a 90-min infusion of PLD $30 \mathrm{mg} / \mathrm{m}^{2}$ followed by a $3-\mathrm{h}$ infusion of trabectedin $1.1 \mathrm{mg} / \mathrm{m}^{2}$ every 3 weeks $(n=333)$. The groups were well matched for baseline characteristics, with $63-65 \%$ of patients classified as platinum sensitive (PFI $\geq 6$ months). The distribution of patients with PFI of 6-12 months and PFI $>12$ months was fairly equal in these groups. PFS was 7.3 months in patients receiving the combination of PLD and trabectedin versus 5.8 months for patients who received PLD alone (HR 0.79, $95 \%$ CI 0.65-0.96, $p=0.0190$ ). Stratifying results according to platinum-resistant or platinum-sensitive status demonstrated that the benefit is observed only in platinum-sensitive patients.

A subgroup analysis showed that the group of patients with a PFI of 6-12 months obtained an increment in OS when treated with trabectedin and PLD than compared to PLD monotherapy [97, 98]. This difference was more evident when platinum was the next regimen used after the progression of the patient to the trial medication, raising the hypothesis that a prolongation of the platinum-free interval by a non-platinum-based regimen could restore the platinum sensitivity and be beneficial for the patient. This hypothesis is the background of the randomized clinical trial INOVATYON (INternational OVArian Cancer Patients Trial With YONdelis), which includes patients with recurrent OC and a PFI of 6-12 months and compares the combination of carboplatin-PLD followed by the regimen selected by the investigator at progression or trabectedin-PLD followed by a platinum-based regimen at progression.

Based on the above-mentioned sub-analysis, the combination of trabectedin and PLD has been proposed as an alternative for patients with a PFI of 6-12 months.

\section{Strategies for the future in ovarian cancer}

The progress in the treatment of OC will be leaded by a better understanding of the biology of the disease and the development of new targeted therapies.

According to the 4th OC Consensus Conference, the most promising areas appear to be the antiangiogenesis and the homologous recombination deficiency [2].

Other promising targets currently being studied based on OC biology include: PI3-kinase and Ras/Raf pathways; folate receptor; and immune targets/cytokines, notch/ hedgehog and IGF, which all merit further investigation.

The Consensus also stated three important principles: (1) the necessity of exploring predictive biomarkers to select the adequate patient for the drugs, (2) one of the priorities should be to understand the mechanism of resistance to new drugs, and (3) targeted agents should be studied both as single agents and in combination based on preclinical data [2].

A review of all the targets, the preliminary clinical results and the ongoing clinical trials is beyond the scope of this article. Figure 4 summarizes the main agents.

However, due to the fact that bevacizumab is the only targeted therapy available for clinical use in ovarian cancer right now, it is worth to make some reflections. Specifically, despite the positive results of ICON-7 and GOG-218, several questions remain to be answered about the use of bevacizumab, at least in the front line of ovarian cancer: 


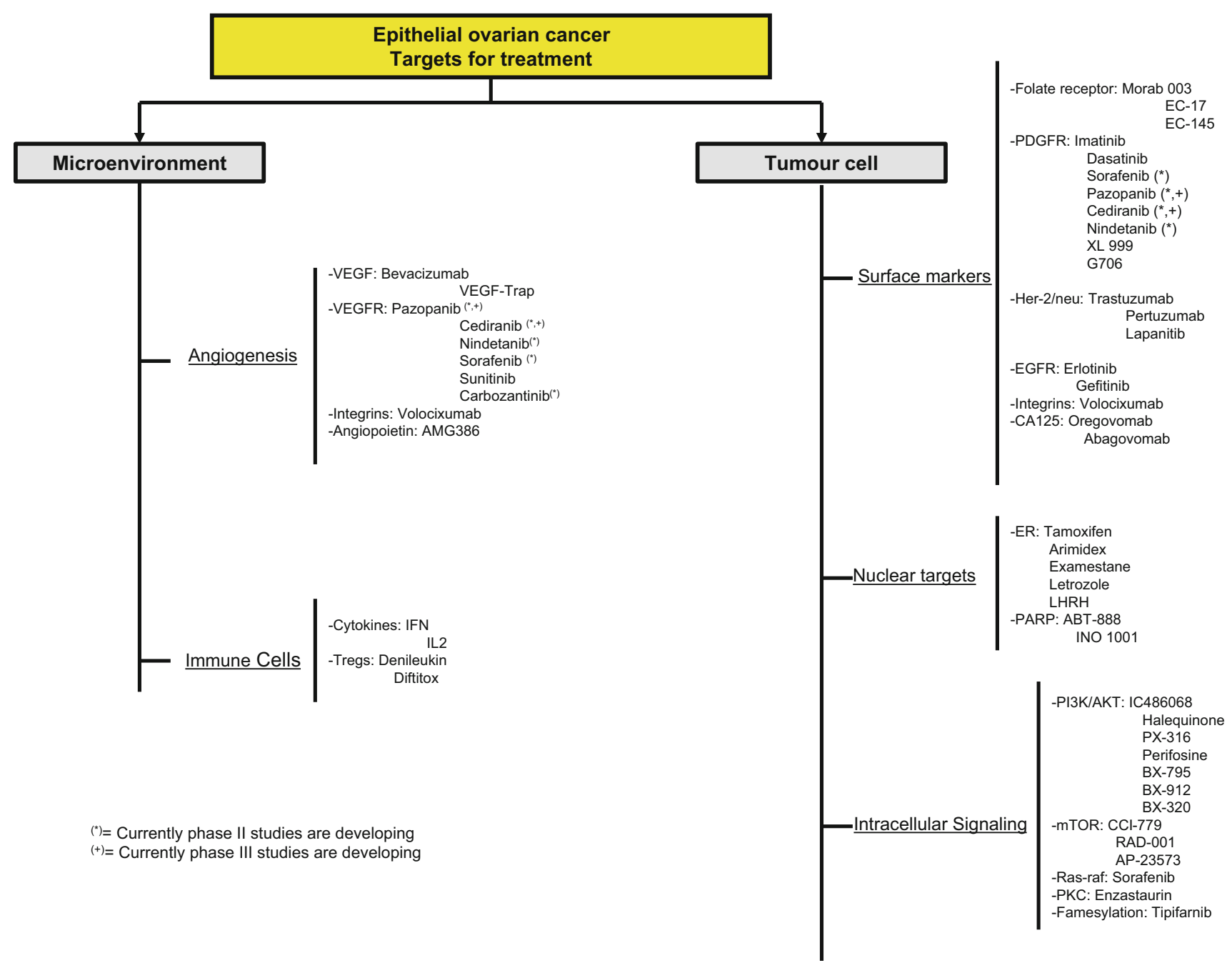

Fig. 4 Target for OC treatment based on OC biology

- Is PFS a valid end-point or should it be OS? This is an important topic but according to the 4th Ovarian Cancer Consensus Conference, the PFS is the preferred endpoint in first line due to the confounding effect of postprogression therapy in ovarian cancer. Nevertheless, OS is still an important endpoint ant it should be maintained in clinical trials when possible.

- Dose selection of bevacizumab? Unfortunately, we do not have an answer for this question, as we have positive results with two different doses (7.5 and $15 \mathrm{mg} / \mathrm{kg}$ ), without any significant difference in toxicity or a randomized comparison that could help to the clinician.

- Optimal duration of bevacizumab? In both trials, the maximum effect was obtained at the moment when bevacizumab was stopped, and this observation has generated the hypothesis that a longer duration of bevacizumab could be associated to a higher benefit. To explore this interesting clinical question, the AGO group has launched a trial comparing 15 months of bevacizumab in the control arm against 30 months in the experimental arm.

- Other important questions that need to be answered in ongoing and future clinical trials are about the role of bevacizumab in second line when it was used in first line, a well-designed pharmaco-economic analysis and the validation of predictive biomarkers. Fortunately, both first line trials were accompanied by an important translational program seeking for predictive biomarkers on the use of bevacizumab.

\section{Methodology in clinical trials}

A large number of new therapies are being studied in OC, presenting additional challenges, in terms of identifying their activity and their place in the treatment. Establishing 
optimal treatment as single agent, or in combination with chemotherapy, or as maintenance treatment, requires new approaches to trial design, selection of meaningful endpoints and carefully conducted trials with translational studies.

A clinical endpoint is a characteristic or variable that reflects how a patient feels, functions, or survives, while a surrogate endpoint is a biomarker or endpoint that is intended to substitute for a clinical endpoint. A good correlate may not make a good surrogate. A surrogate endpoint is expected to predict clinical benefit (or harm), or lack thereof [99].

The 2010 Gynecologic Cancer InterGroup (GCIG) consensus statement on clinical trials in OC includes a review of the latest evidence from high-quality clinical trials [2].

Appropriate endpoints for clinical trials should reflect the achievement of clinical benefit, which is defined as improvement of one or more of the following subjective and objective endpoints: toxicity, time without symptoms, patient-reported outcomes (PRO), PFS, overall survival (OS). Cost effectiveness should be evaluated when feasible [2].

We should assess the meaningful endpoints in different OC settings for phase III trials. In adjuvant trials for early disease, RFS (recurrence free survival) is a valid surrogate for OS. In first line for advance disease, PFS is a valid surrogate for OS for trials with chemotherapy. As mentioned before, PFS is the preferred endpoint because of the confounding effect of post-progression therapy. However, when possible, the study should be powered to allow proper assessment of both PFS and OS. Finally, how the PFS is defined should be established with regard to method (CA-125; RECIST) and timing of evaluation.

In platinum-sensitive relapse, if PFS is used as primary endpoint, trials should be powered for OS as co-primary endpoint, otherwise OS is the preferred primary endpoint for phase III trials [2].

In resistant-refractory, we will consider composite endpoints involving QoL aspects due to clinical relevance of the patients [2]. Secondary endpoints may include objective response rate, percent survival at 6 months, health-related quality of life, PRO, time without symptoms or toxicity, and pharmacoeconomic analyses. PFS is the preferred endpoint (over ORR at a time point) and ORR is not a validated endpoint when testing new agents.

The conference addresses a number of molecular markers as surrogate outcomes and predictive factors; however, although most of these markers hold significant promise, there is no standard molecular profile that must be included in all trials. It was recommended that the collection of biological specimens be considered in each and every clinical trial at predetermined intervals. This recognizes that there are multiple issues to be addressed and harmonized in the collection of tissues in different jurisdictions and central analysis [2].

\section{Cooperation in research in Gynecological Oncology}

To organize, stimulate and coordinate clinical research studies on gynecological cancer in general, but especially on ovarian cancer, multidisciplinary specialist networks need to be set up which can then form working subgroups with the participation of oncologists, surgeons, pathologists, pharmacoeconomic specialists, epidemiologists, etc.

Society meetings should promote academic clinical trials, disseminate the results of important trials, and facilitate the development and coordination of new trials. Finally, the leadership of our sister societies should meet several times a year to share information and coordinate educational programmes. We must continue to work together to reduce the global burden of gynecological cancer.

\section{Conflict of interest None.}

Open Access This article is distributed under the terms of the Creative Commons Attribution License which permits any use, distribution, and reproduction in any medium, provided the original author(s) and the source are credited.

\section{References}

1. Poveda Velasco A, Casado Herráez A, Cervantes Ruipérez A, Gallardo Rincón D, García García E, González Martín A, GEICO Group et al (2007) Treatment guidelines in ovarian cancer. Clin Transl Oncol 9(5):308-316

2. Stuart GC, Kitchener H, Bacon M, duBois A, Friedlander M, Ledermann J et al (2011) 2010 Gynecologic Cancer InterGroup (GCIG) consensus statement on clinical trials in ovarian cancer: report from the Fourth Ovarian Cancer Consensus Conference. Int J Gynecol Cancer 21:750-755

3. Khan AR, Khan S, Zimmerman V, Baddour LM, Tleyjeh IM (2010) Quality and strength of evidence of the Infectious Diseases Society of America clinical practice guidelines. Clin Infect Dis 51(10):1147-1156

4. American College of Obstetricians and Gynecologists (2007) ACOG Practice Bulletin. Management of adnexal masses. Obstet Gynecol 110(1):201-214

5. Guerriero S, Alcazar JL, Ajossa S, Galvan R, Laparte C, García-Manero M et al (2010) Transvaginal color Doppler imaging in the detection of ovarian cancer in a large study population. Int J Gynecol Cancer 20(5):781-786

6. Gentry-Maharaj A, Menon U (2012) Screening for ovarian cancer in the general population. Best Pract Res Clin Obstet Gynaecol 26(2):243-256

7. Van Gorp T, Veldman J, Van Calster B, Cadron I, Leunen K, Amant F et al (2012) Subjective assessment by ultrasound is superior to the risk of malignancy index (RMI) or the risk of ovarian malignancy algorithm (ROMA) in discriminating benign from malignant adnexal masses. Eur J Cancer 48(11):1649_ 1656

8. Bharwani N, Reznek RH, Rockall AG (2011) Ovarian Cancer Management: the role of imaging and diagnostic challenges. Eur J Radiol 78(1):41-51

9. Fagotti A, Ferrandina G, Fanfani F, Garganese G, Vizzielli G, Carone V et al (2008) Prospective validation of a laparoscopic predictive model for optimal cytoreduction in advanced ovarian carcinoma. Am J Obstet Gynecol 199(6):642.e1-642.e6

10. Menon U, Gentry-Maharaj A, Hallett R, Ryan A, Burnell M, Sharma A et al (2009) Sensitivity and specificity of multimodal and ultrasound screening for ovarian cancer, and stage distribution of detected cancers: results of the prevalence screen of the UK Collaborative Trial of Ovarian Cancer Screening (UKCTOCS). Lancet Oncol 10(4):327-340

11. Nagell JR Jr, DePriest PD, Ueland FR, DeSimone CP, Cooper AL, McDonald JM et al (2007) Ovarian cancer screening with annual transvaginal sonography: findings of 25,000 women screened. Cancer 109(9):1887-1896 
12. Buys SS, Partridge E, Black A, Johnson CC, Lamerato L, Isaacs C, PLCO Project Team et al (2011) Effect of screening on ovarian cancer mortality: the Prostate, Lung, Colorectal and Ovarian (PLCO) Cancer Screening Randomized Controlled Trial. JAMA 305(22):2295-2303

13. Rosenthal A, Jacobs I (2006) Familial ovarian cancer screening. Best Pract Res Clin Obstet Gynaecol 20(2):321-338

14. Boyd J (2003) Specific keynote: hereditary ovarian cancer: what we know. Gynecol Oncol 88(1 pt 2): S8-S10 (discussion S1-S3)

15. Kaur M, Radovanovic A, Essack M, Schaefer U, Maqungo M, Kibler T et al (2009) Database for exploration of functional context of genes implicated in ovarian cancer. Nucleic Acids Res 37(Database issue):D820-D823

16. Pennington KP, Swisher EM (2012) Hereditary ovarian cancer: beyond the usual suspects. Gynecol Oncol 124(2):347-353

17. Bolton KL, Chenevix-Trench G, Goh C, Sadetzki S, Ramus SJ, Karlan BY et al (2012) Association between BRCA1 and BRCA2 mutations and survival in women with invasive epithelial ovarian cancer. JAMA 307(4):382-390

18. Evans DG, Shenton A, Woodward E, Lalloo F, Howell A, Maher ER (2008) Penetrance estimates for BRCA1 and BRCA2 based on genetic testing in a Clinical Cancer Genetics service setting: risks of breast/ovarian cancer quoted should reflect the cancer burden in the family. BMC Cancer 30(8):155

19. Zon RT, Goss E, Vogel VG, Chlebowski RT, Jatoi I, Robson ME et al (2009) American Society of Clinical Oncology policy statement: the role of the oncologist in cancer prevention and risk assessment. J Clin Oncol 27(6):986-993

20. Vasen HFA, Watson P, Mecklin J-P, Lynch HT (1999) New clinical criteria for hereditary nonpolyposis colorectal cancer (HNPCC, Lynch syndrome) proposed by the International Collaborative Group on Hereditary Nonpolyposis Colorectal Cancer. Gastroenterology 116:1453-1456

21. Umar A, Boland CR, Terdiman JP, Syngal S, de la Chapelle A, Rüschoff J et al (2004) Revised Bethesda Guidelines for Hereditary Nonpolyposis Colorectal Cancer (Lynch syndrome) and microsatellite instability. J Natl Cancer Inst 96:261-268

22. Robson ME, Storm CD, Weitzel J, Wollins DS, American Society of Clinical Oncology (2010) American Society of Clinical Oncology policy statement update: genetic and genomic testing for cancer susceptibility. J Clin Oncol 28(5):893-901

23. Przybycin CG, Kurman RJ, Ronnett BM, Shih IeM, Vang R (2010) Are all pelvic (nonuterine) serous carcinomas of tubal origin? Am J Surg Pathol 34:1407-1416

24. Vicus D, Finch A, Cass I, Rosen B, Murphy J, Fan I et al (2010) Prevalence of BRCA1 and BRCA2 germ line mutations among women with carcinoma of the fallopian tube. Gynecol Oncol 118(3):299-302

25. Lin KM, Shashidharan M, Thorson AG, Ternent CA, Blatchford GJ, Christensen MA et al (1998) Cumulative incidence of colorectal and extracolonic cancers in MLH1 and MSH2 mutation carriers of hereditary nonpolyposis colorectal cancer. J Gastrointest Surg 2(1):67-71

26. Domchek SM, Friebel TM, Singer CF, Evans DG, Lynch HT, Isaacs C et al (2010) Association of risk-reducing surgery in BRCA1 or BRCA2 mutation carriers with cancer risk and mortality. JAMA 304(9):967-975

27. Rebbeck TR, Kauff ND, Domchek SM (2009) Meta-analysis of risk reduction estimates associated with risk-reducing salpingo-oophorectomy in BRCA1 or BRCA2 mutation carriers. J Natl Cancer Inst 101(2):80-87

28. Norquist BM, Garcia RL, Allison KH, Jokinen CH, Kernochan LE, Pizzi CC et al (2010) The molecular pathogenesis of hereditary ovarian carcinoma: alterations in the tubal epithelium of women with BRCA1 and BRCA2 mutations. Cancer 116(22):5261-5271

29. Kurman RJ, Shih I (2010) The origin and pathogenesis of epithelial ovarian cancer: a proposed unifying theory. Am J Surg Pathol 34:433-443

30. Seidman JD, Horkayne-Szakaly I, Haiba M, Boice CR, Kurman RJ, Ronnett BM (2004) The histologic type and stage distribution of ovarian carcinomas of surface epithelial origin. Int J Gynecol Pathol 23:41-44

31. Shih I, Kurman RJ (2004) Ovarian tumorigenesis: a proposed model based on morphological and molecular genetic analysis. Am J Pathol 164:1511-1518

32. Singer G, Stohr R, Cope L, Dehari R, Hartmann A, Cao DF et al (2005) Patterns of p53 mutations separate ovarian serous borderline tumors and low- and highgrade carcinomas and provide support for a new model of ovarian carcinogenesis: a mutational analysis with immunohistochemical correlation. Am J Surg Pathol 29:218-224

33. Prat J (2012) New insights into ovarian cancer pathology. Ann Oncol 23(Suppl 10):x111-x117

34. Cancer Genome Atlas Research Network (2011) Integrated genomic analyses of ovarian carcinoma.The Cancer Genome Atlas Research Network. Nature 474:609-615

35. Young RH, Gilks CB, Scully RE (1991) Mucinous tumors of the appendix associated with mucinous tumors of the ovary and pseudomyxoma peritonei. A clinicopathological analysis of 22 cases supporting an origin in the appendix. Am J Surg Pathol 15:415-429

36. Bocker W (2002) WHO classification of breast tumors and tumors of the female genital organs: pathology and genetics. Verh Dtsch Ges Pathol 86:116-119

37. Sato N, Tsunoda H, Nishida M, Morishita Y, Takimoto Y, Kubo T et al (2000) Loss of heterozygosity on 10q23.3 and mutation of the tumor suppressor gene PTEN in benign endometrial cyst of the ovary: possible sequence progression from benign endometrial cyst to endometrioid carcinoma and clear cell carcinoma of the ovary. Cancer Res 60:7052-7056

38. Merritt MA, Cramer DW (2011) Molecular pathogenesis of endometrial and ovarian cancer. Cancer Biomark 9:287-305

39. Kim KR, Choi J, Hwang JE, Baik YA, Shim JY, Kim YM et al (2010) Endocervical-like (Mullerian) mucinous borderline tumours of the ovary are frequently associated with the KRAS mutation. Histopathology 57:587-596

40. Wiegand KC, Shah SP, Al-Agha OM, Zhao Y, Tse K, Zeng T et al (2010) ARID1A mutations in endometriosis-associated ovarian carcinomas. N Engl J Med 363:1532-1543

41. Wheeler DT (2004) Borderline ovarian tumors: a web-based atlas. Adv Anat Pathol 11:322

42. Goff BA, Matthews BJ, Larson EH, Andrilla CH, Wynn M, Lishner DM et al (2007) Predictors of comprehensive surgical treatment in patients with ovarian cancer. Cancer 109(10):2031-2042

43. Trimbos B, Timmers P, Pecorelli S, Coens C, Ven K, van der Burg M et al (2010) Surgical staging and treatment of early ovarian cancer: long-term analysis from a randomized trial. J Natl Cancer Inst 102(13):982-987

44. Leblanc E, Querleu D, Narducci F, Occelli B, Papageorgiou T, Sonoda Y (2004) Laparoscopic restaging of early stage invasive adnexal tumors: a 10-year experience. Gynecol Oncol 94(3):624-629

45. Ng JS, Low JJ, Ilancheran A (2012) Fertility preservation in gynaecological cancer: epithelial ovarian cancer. Best Pract Res Clin Obstet Gynaecol 26(3):337-345

46. Morice P, Denschlag D, Rodolakis A, Reed N, Schneider A, Kesic V et al (2011) Fertility Task Force of the European Society of Gynecologic Oncology. Recommendations of the Fertility Task Force of the European Society of Gynecologic Oncology about the conservative management of ovarian malignant tumors. Int J Gynecol Cancer 21(5):951-963

47. Eisenhauer EL, Abu-Rustum NR, Sonoda Y, Levine DA, Poynor EA, Aghajanian $\mathrm{C}$ et al (2006) The addition of extensive upper abdominal surgery to achieve optimal cytoreduction improves survival in patients with stages IIIC-IV epithelial ovarian cancer. Gynecol Oncol 103(3):1083-1090

48. du Bois A, Reuss A, Pujade-Lauraine E, Harter P, Ray-Coquard I, Pfisterer J (2009) Role of surgical outcome as prognostic factor in advanced epithelia ovarian cancer: a combined exploratory analysis of 3 prospectively randomized phase 3 multicenter trials: by the Arbeitsgemeinschaft Gynaekologische Onkologie Studiengruppe Ovarialkarzinom (AGO-OVAR) and the Groupe d'Investigateurs Nationaux Pour les Etudes des Cancers de l'Ovaire (GINECO). Cancer 115(6): 1234-1244

49. Elattar A, Bryant A, Winter-Roach BA, Hatem M, Naik R (2011) Optima primary surgical treatment for advanced epithelial ovarian cancer. Cochrane Database Syst Rev (8):CD007565. doi:10.1002/14651858.CD007565.pub2

50. Fotopoulou C, Richter R, Braicu EI, Schmidt SC, Lichtenegger W, Sehouli J (2010) Can complete tumor resection be predicted in advanced primary epithelial ovarian cancer? A systematic evaluation of 360 consecutive patients. Eur J Surg Oncol 36(12):1202-1210

51. Shih KK, Chi DS (2010) Maximal cytoreductive effort in epithelial ovarian cancer surgery. J Gynecol Oncol 21(2):75-80

52. Chi DS, Musa F, Dao F, Zivanovic O, Sonoda Y, Leitao MM et al (2012) An analysis of patients with bulky advanced stage ovarian, tubal, and peritoneal carcinoma treated with primary debulking surgery (PDS) during an identical time period as the randomized EORTC-NCIC trial of PDS vs neoadjuvant chemotherapy (NACT). Gynecol Oncol 124(1):10-14

53. Armstrong DK, Bundy B, Wenzel L, Huang HQ, Baergen R, Lele S, Gynecologic Oncology Group et al (2006) Intraperitoneal cisplatin and paclitaxel in ovarian cancer. N Engl J Med 354(1):34-43

54. Trimbos JB, Parmar M, Vergote I, Guthrie D, Bolis G, Colombo N et al (2003) International Collaborative Ovarian Neoplasm trial 1 and Adjuvant ChemoTherapy in Ovarian Neoplasm trial: two parallel randomized phase III trials of adjuvant chemotherapy in patients with early-stage ovarian carcinoma. J Natl Cancer Inst 95:105-112

55. Colombo N, Guthrie D, Chiari S, Parmar M, Qian W, Swart AM et al (2003) International Collaborative Ovarian Neoplasm trial 1: a randomized trial of adjuvant chemotherapy in women with early-stage ovarian cancer. J Natl Cancer Inst 95:125-132

56. (1998) ICON2: randomised trial of single-agent carboplatin against three-drug combination of CAP (cyclophosphamide, doxorubicin, and cisplatin) in women with ovarian cancer. ICON Collaborators International Collaborative Ovarian Neoplasm Study. Lancet 352:1571-1576

57. Bell J, Brady MF, Young RC, Lage J, Walker JL, Look KY et al (2006) Randomized phase III trial of three versus six cycles of adjuvant carboplatin and paclitaxel in early stage epithelial ovarian carcinoma: a Gynecologic Oncology Group study. Gynecol Oncol 102:432-439

58. Trimbos JB, Vergote I, Bolis G, Vermorken JB, Mangioni C (2003) Impact of adjuvant chemotherapy and surgical staging in early-stage ovarian carcinoma: European Organisation for Research and Treatment of Cancer-Adjuvant ChemoTherapy in Ovarian Neoplasm trial. J Natl Cancer Inst 95(2):113-125

59. Young RC, Walton LA, Ellenberg SS, Homesley HD, Wilbanks GD, Decker DG et al (1990) Adjuvant therapy in stage I and stage II epithelial ovarian cancer. Results of two prospective randomized trials. $\mathrm{N}$ Engl $\mathrm{J}$ Med $322: 1021-1027$ 
60. Leonard R, Ballinger R, Cameron D, Ellis P, Fallowfield L, Gosney M, Johnson L et al (2011) Adjuvant chemotherapy in older women (ACTION) study-what did we learn from the pilot phase? Br J Cancer 105(9):1260-1266

61. Berek JS, Bertelsen K, du Bois A, Brady MF, Carmichael J, Eisenhauer EA et al (2000) [Epithelial ovarian cancer (advanced stage): consensus conference (1998)]. Gynecol Obstet Fertil 28:576-583

62. Ozols RF (2000) Optimum chemotherapy for ovarian cancer. Int J Gynecol Cancer 10:33-37

63. Thigpen T, duBois A, McAlpine J, DiSaia P, Fujiwara K, Hoskins W et al (2011) First-line therapy in ovarian cancer trials. Int J Gynecol Cancer 21:756-762

64. McGuire WP, Hoskins WJ, Brady MF, Kucera PR, Partridge EE, Look KY et al (1996) Cyclophosphamide and cisplatin versus paclitaxel and cisplatin: a phase III randomized trial in patients with suboptimal stage III/IV ovarian cancer (from the Gynecologic Oncology Group). Semin Oncol 23:40-47

65. Piccart MJ, Bertelsen K, James K, Cassidy J, Mangioni C, Simonsen E et al (2000) Randomized intergroup trial of cisplatin-paclitaxel versus cisplatincyclophosphamide in women with advanced epithelial ovarian cancer: threeyear results. J Natl Cancer Inst 92:699-708

66. Adams M, Calvert AH, Carmichael J, Clark PI, Coleman RE, Earl HM et al (1998) Chemotherapy for ovarian cancer-a consensus statement on standard practice. Br J Cancer 78:1404-1406

67. Ozols RF, Bundy BN, Greer BE, Fowler JM, Clarke-Pearson D, Burger RA et al (2003) Phase III trial of carboplatin and paclitaxel compared with cisplatin and paclitaxel in patients with optimally resected stage III ovarian cancer: a Gynecologic Oncology Group study. J Clin Oncol 21:3194-3200

68. du Bois A, Lück HJ, Meier W, Adams HP, Möbus V, Costa S et al (2003) A randomized clinical trial of cisplatin/paclitaxel versus carboplatin/paclitaxel as first-line treatment of ovarian cancer. J Natl Cancer Inst 95:1320-1329

69. Neijt JP, Engelholm SA, Tuxen MK, Sorensen PG, Hansen M, Sessa C et al (2000) Exploratory phase III study of paclitaxel and cisplatin versus paclitaxel and carboplatin in advanced ovarian cancer. J Clin Oncol 18:3084-3092

70. Pignata S, Scambia G, Ferrandina G, Savarese A, Sorio R, Breda E et al (2011) Carboplatin plus paclitaxel versus carboplatin plus pegylated liposomal doxorubicin as first-line treatment for patients with ovarian cancer: the MITO-2 randomized phase III trial. J Clin Oncol 29:3628-3635

71. du Bois A, Weber B, Rochon J, Meier W, Goupil A, Olbricht S et al (2006) Addition of epirubicin as a third drug to carboplatin-paclitaxel in first-line treatment of advanced ovarian cancer: a prospectively randomized gynecologic cancer intergroup trial by the Arbeitsgemeinschaft Gynaekologische Onkologie Ovarian Cancer Study Group and the Groupe d'Investigateurs Nationaux pour l'Etude des Cancers Ovariens. J Clin Oncol 24:1127-1135

72. Bookman MA, Brady MF, McGuire WP, Harper PG, Alberts DS, Friedlander M et al (2009) Evaluation of new platinum-based treatment regimens in advancedstage ovarian cancer: a Phase III Trial of the Gynecologic Cancer Intergroup. J Clin Oncol 27:1419-1425

73. du Bois A, Herrstedt J, Hardy-Bessard AC, Müller HH, Harter P, Kristensen G et al (2010) Phase III trial of carboplatin plus paclitaxel with or without gemcitabine in first-line treatment of epithelial ovarian cancer. J Clin Oncol 28:4162-4169

74. Hoskins PJ (2009) Triple cytotoxic therapy for advanced ovarian cancer: a failed application, not a failed strategy. J Clin Oncol 27:1355-1358

75. Pfisterer J, Weber B, Reuss A, Kimmig R, du Bois A, Wagner U et al (2006) Randomized phase III trial of topotecan following carboplatin and paclitaxel in first-line treatment of advanced ovarian cancer: a gynecologic cancer intergroup trial of the AGO-OVAR and GINECO. J Natl Cancer Inst 98:1036-1045

76. Verheijen RH, Massuger LF, Benigno BB, Epenetos AA, Lopes A, Soper JT et al (2006) Phase III trial of intraperitoneal therapy with yttrium-90-labeled HMFG1 murine monoclonal antibody in patients with epithelial ovarian cancer after a surgically defined complete remission. J Clin Oncol 24:571-578

77. Markman M, Liu PY, Wilczynski S, Monk B, Copeland LJ, Alvarez RD et al (2003) Phase III randomized trial of 12 versus 3 months of maintenance paclitaxel in patients with advanced ovarian cancer after complete response to platinum and paclitaxel-based chemotherapy: a Southwest Oncology Group and Gynecologic Oncology Group trial. J Clin Oncol 21:2460-2465

78. Pecorelli S, Favalli G, Gadducci A, Katsaros D, Panici PB, Carpi A et al (2009) Phase III trial of observation versus six courses of paclitaxel in patients with advanced epithelial ovarian cancer in complete response after six courses of paclitaxel/platinum-based chemotherapy: final results of the After-6 protocol 1. J Clin Oncol 27:4642-4648

79. Bristow RE, Chi DS (2006) Platinum-based neoadjuvant chemotherapy and interval surgical cytoreduction for advanced ovarian cancer: a meta-analysis. Gynecol Oncol 103:1070-1076

80. Vergote I, Trope CG, Amant F, Kristensen GB, Ehlen T, Johnson N et al (2010) Neoadjuvant chemotherapy or primary surgery in stage IIIC or IV ovarian cancer. N Engl J Med 363:943-953
81. Katsumata N, Yasuda M, Takahashi F, Isonishi S, Jobo T, Aoki D et al (2009) Dose-dense paclitaxel once a week in combination with carboplatin every 3 weeks for advanced ovarian cancer: a phase 3, open-label, randomised controlled trial. Lancet 374:1331-1338

82. Katsumata N, Yasuda M, Isonishi S, Michimae H, Kimura E, Aoki D et al (2012) Long-term follow-up of a randomized trial comparing conventional paclitaxel and carboplatin with dose-dense weekly paclitaxel and carboplatin in women with advanced epithelial ovarian, fallopian tube, or primary peritoneal cancer: JGOG 3016 trial. J Clin Oncol 30 (Suppl; abstr 5003)

83. Alberts DS, Liu PY, Hannigan EV, O'Toole R, Williams SD, Young JA et al (1996) Intraperitoneal cisplatin plus intravenous cyclophosphamide versus intravenous cisplatin plus intravenous cyclophosphamide for stage III ovarian cancer. N Engl J Med 335(26):1950-1955

84. Markman M, Bundy BN, Alberts DS, Fowler JM, Clark-Pearson DL, Carson LF et al (2001) Phase III trial of standard-dose intravenous cisplatin plus paclitaxel versus moderately high-dose carboplatin followed by intravenous paclitaxel and intraperitoneal cisplatin in small-volume stage III ovarian carcinoma: an intergroup study of the Gynecologic Oncology Group, Southwestern Oncology Group, and Eastern Cooperative Oncology Group. J Clin Oncol 19(4):10011007

85. Armstrong DK, Bundy B, Wenzel L, Huang HQ, Baergen R, Lele S et al (2006) Intraperitoneal cisplatin and paclitaxel in ovarian cancer. $\mathrm{N}$ Engl $\mathrm{J}$ Med 354:34-43

86. Jaaback K, Johnson N, Lawrie TA (2011) Intraperitoneal chemotherapy for the initial management of primary epithelial ovarian cancer. Cochrane Database Syst Rev 11:CD005340. doi:10.1002/14651858.CD005340.pub3

87. Perren TJ, Swart AM, Pfisterer J, Ledermann JA, Pujade-Lauraine E, Kristensen $\mathrm{G}$ et al (2011) A phase 3 trial of bevacizumab in ovarian cancer. N Engl J Med 365:2484-2496

88. Burger RA, Brady MF, Bookman MA, Fleming GF, Monk BJ, Huang $\mathrm{H}$ et al (2011) Incorporation of bevacizumab in the primary treatment of ovarian cancer. N Engl J Med 365:2473-2483

89. Rustin GJ, van der Burg ME, Griffin CL, Guthrie D, Lamont A, Jayson GC et al (2010) Early versus delayed treatment of relapsed ovarian cancer (MRC OV05/ EORTC 55955): a randomised trial. Lancet 376:1155-1163

90. Lauraine EP, Hilpert F, Weber B, Reuss A, Poveda A, Kristensen G et al (2012) AURELIA: a randomized phase III trial evaluating bevacizumab (BEV) plus chemotherapy (CT) for platinum (PT)-resistant recurrent ovarian cancer (OC). J Clin Oncol 30 (suppl; abstr LBA5002^)

91. Parmar MK, Ledermann JA, Colombo N, du Bois A, Delaloye JF, Kristensen GB et al (2003) Paclitaxel plus platinum-based chemotherapy versus conventional platinum-based chemotherapy in women with relapsed ovarian cancer: the ICON4/AGO-OVAR-2.2 trial. Lancet 361:2099-2106

92. Gonzalez-Martin AJ, Calvo E, Bover I, Rubio MJ, Arcusa A, Casado A et al (2005) Randomized phase II trial of carboplatin versus paclitaxel and carboplatin in platinum-sensitive recurrent advanced ovarian carcinoma: a GEICO (Grupo Espanol de Investigacion en Cancer de Ovario) study. Ann Oncol 16:749-755

93. Pfisterer J, Plante M, Vergote I, du Bois A, Hirte H, Lacave AJ et al (2006) Gemcitabine plus carboplatin compared with carboplatin in patients with platinum-sensitive recurrent ovarian cancer: an intergroup trial of the AGO-OVAR, the NCIC CTG, and the EORTC GCG. J Clin Oncol 24:4699-4707

94. Pujade-Lauraine E, Wagner U, Aavall-Lundqvist E, Gebski V, Heywood M Vasey PA et al (2010) Pegylated liposomal doxorubicin and carboplatin compared with paclitaxel and carboplatin for patients with platinum-sensitive ovarian cancer in late relapse. J Clin Oncol 28:3323-3329

95. Aghajanian C, Blank SV, Goff BA, Judson PL, Teneriello MG, Husain A et al (2012) OCEANS: a randomized, double-blind, placebo-controlled phase III tria of chemotherapy with or without bevacizumab in patients with platinum-sensitive recurrent epithelial ovarian, primary peritoneal, or fallopian tube cancer J Clin Oncol 30:2039-2045

96. Monk BJ, Herzog TJ, Kaye S, Krasner CN, Vermorken JB, Muggia FM et al (2010) Trabectedin plus pegylated liposomal doxorubicin in recurrent ovarian cancer. J Clin Oncol 28:3107-3114

97. Poveda A, Vergote I, Tjulandin S, Kong B, Roy M, Chan S et al (2011) Trabectedin plus pegylated liposomal doxorubicin in relapsed ovarian cancer: outcomes in the partially platinum-sensitive (platinum-free interval 6-12 months) subpopulation of OVA-301 phase III randomized trial. Ann Oncol 22(1):39-48

98. Colombo N (2011) Efficacy of trabectedin in platinum-sensitive-relapsed ovarian cancer: new data from the randomized OVA-301 study. Int J Gynecol Cancer 21(Suppl 1):S12-S16

99. Biomarkers Definitions Working Group (2001) Biomarkers and surrogate endpoints: preferred definitions and conceptual framework. Clin Pharmacol Ther 69:89-95 